\title{
CHARACTERIZATION AND CLASSIFICATION OF MEDICINAL PLANT EXTRACTS ACCORDING TO THEIR ANTIOXIDANT ACTIVITY USING HIGH-PERFORMANCE LIQUID CHROMATOGRAPHY AND MULTIVARIATE ANALYSIS
}

\author{
ILEANA M. SIMIONa, AUGUSTIN C. MOT! \\ RADU D. GĂCEANU ${ }^{b}$, HORIA F. POP ${ }^{b}$, COSTEL SÂRBU $^{a^{*}}$
}

\begin{abstract}
Fuzzy divisive hierarchical clustering (FDHC) alongside with principal component analysis, hierarchical cluster analysis and linear discriminant analysis are efficiently employed for the characterization and clustering of some medicinal plants according to their antioxidant capacity. These methods are applied to the numerical data obtained from the chromatographic profiles monitored at 242, 260, 280,320, 340 and $380 \mathrm{~nm}$ by high-performance liquid chromatography with a multistep isocratic and gradient elution system and diode array detection (HPLC-DAD). The samples were successfully classified according to the antioxidant activity determined using the DPPH assay. A correct classification rate of $100 \%$ was obtained when the samples were divided into two groups corresponding to high antioxidant activity and low antioxidant activity. Moreover, it is suggested to use the scores obtained applying principal component analysis and unprocessed data (the processed data by scaling and normalization did not improve the results), the analysis being faster with the same results. The proposed methodology could be considered as a promising tool with future applications in plant material investigations and other analytical fields.
\end{abstract}

Keywords: Fuzzy clustering, chemometrics, high-performance liquid chromatography, antioxidant capacity, medicinal plants

\section{INTRODUCTION}

Nature has always involved in human development providing the necessary means in order to live a healthy and careless live through natural resource such as fruits, vegetables or medicinal plants. Herbal medicine, as

\footnotetext{
a Babeş-Bolyai University, Faculty of Chemistry and Chemical Engineering, 11 Arany Janos str., RO-400028, Cluj-Napoca, Romania

b Babeș-Bolyai University, Department of Computer Science, str. Mihail Kogalniceanu nr. 1, 400084, Cluj-Napoca, Romania

* Corresponding author: csarbu@chem.ubbcluj.ro
} 
the name suggests, uses plants as a replacement for chemically synthesized drugs, because they are cheaper, less toxic and have no side effects. The medicinal plant's therapeutic properties are sustained by the bioactive compounds that are produced through different processes that take place in the plant's cells called secondary metabolites. Thanks to the so-called secondary metabolites represented by alkaloids, sterols, terpenes, flavonoids, tannins, glycosides, resins, volatile oils, etc., the alternative medicine started to play an important role in the treatment of diseases all over the world, mostly because the medicinal system in many underdeveloped countries is still inexistent. Due to the above-mentioned considerations, the World Health Organization (WHO) has developed a strategic plan to promote alternative medicine by publishing four volumes containing 118 monographs regarding medicinal plants. The main purpose of $\mathrm{WHO}$ is to train people to develop their monographs due to the diversity of the flora that is characteristic from one territory to another [1-12].

It is also well known that the medicinal plants act as radical scavengers of free radicals that appear in the human body through metabolism, pollution, contaminants and different medical treatments, factors that lead to the appearance of some serious diseases such as diabetes, cancer or neurological disorders. The composition and antioxidant activity of plant extracts has been determined using various spectrophotometric or chromatographic methods $[3,8,13,14]$. However, high-performance liquid chromatography (HPLC) is recommended by WHO and European Medicine Agency (EMA) for analysis of plant-based samples (additives, toxins, residues or food adulteration) [1521]. Using these methodologies, a large volume of data may result leading to a difficult or even impossible interpretation of the obtained results, therefore chemometric methods like principal component analysis (PCA), hierarchical cluster analysis (HCA) or linear discriminant analysis (LDA) are successfully employed [22-26].

Considering all the above, the aim of this study is to characterize and classify 42 hydroalcoholic extracts prepared from medicinal plants using the chromatographic profile obtained at 242, 260, 280, 320, 340 and $380 \mathrm{~nm}$ according to the antioxidant capacity obtained using the 2,2-diphenyl-1picrylhydrazyl (DPPH') procedure.

\section{RESULTS AND DISCUSSION}

The 42 samples of the commercially available plant extracts from the Romanian flora subjected to a comprehensive holistic characterization and classification according to their antioxidant activity estimated by radical scavenging assay using the 2,2-diphenyl-1-picrylhydrazyl (DPPH ${ }^{*}$ ) procedure and chromatographic profiles are presented in Table 1. 
Table 1. Name and total radical scavenging capacity (RSC \%) determined by $\mathrm{DPPH}^{\circ}$ assay of the investigated hydroalcoholic extracts

\begin{tabular}{|c|c|c|c|c|}
\hline No. & Name & Scientific name & $\begin{array}{c}\text { RSC }^{*} \\
\%\end{array}$ & $\begin{array}{c}\text { Antioxidant } \\
\text { activity }\end{array}$ \\
\hline 1 & Blueberry & Vaccinium myrtillus & 46.71 & High \\
\hline 2 & Lingon berry & Vaccinium vitis-idaea & 36.58 & High \\
\hline 3 & Rosemary & Rosmarinus officinalis & 31.01 & High \\
\hline 4 & Hoary willowherb & Epilobium parviflorum & 29.82 & High \\
\hline 5 & Lady's mantel & Alchemilla vulgaris & 29.61 & High \\
\hline 6 & Quaking aspen & Plopus nigra & 27.97 & High \\
\hline 7 & Lemon balm & Melissa officinalis & 27.36 & High \\
\hline 8 & Sage & Salvia officinalis & 27.36 & High \\
\hline 9 & Silver brich & Betula pendula & 26.27 & High \\
\hline 10 & Saint John's wort & Hypericum perforatum & 21.12 & Moderate \\
\hline 11 & Hawthorn & Crataegus monogyma & 18.74 & Moderate \\
\hline 12 & Breckland thyme & Thymus serpyllum & 15.48 & Moderate \\
\hline 13 & Burdock & Arctium lappa & 13.98 & Moderate \\
\hline 14 & Great celandine & Chelidonium majus & 12.86 & Moderate \\
\hline 15 & Lady's bedstraw & Galium verum & 11.16 & Moderate \\
\hline 16 & Common juniper & Juniperus communis & 10.13 & Moderate \\
\hline 17 & Yarrow & Achillea millefolium & 9.45 & Moderate \\
\hline 18 & Spinycockle-bur & Xanthium spinosum & 9.44 & Moderate \\
\hline 19 & Lavender & Lavandula augustifolia & 8.93 & Moderate \\
\hline 20 & Artichoke & Cynara scolymus & 7.42 & Moderate \\
\hline 21 & Liquorice & Glycyrrhiza glabra & 4.93 & Low \\
\hline 22 & Gentian & Gentiana asclepiadea & 4.46 & Low \\
\hline 23 & Echinacea & Echinacea purpurea & 4.38 & Low \\
\hline 24 & Comfrey & Symphytum officinale & 4.32 & Low \\
\hline 25 & Milk thistle & Silybum marianum & 3.75 & Low \\
\hline 26 & Nettle & Urtica dioica & 3.69 & Low \\
\hline 27 & Heart's ease & Viola tricolor & 3.06 & Low \\
\hline 28 & Motherwort & Leonurus cardiaca & 2.78 & Low \\
\hline 29 & Ginger & Zingiber officinale & 2.26 & Low \\
\hline 30 & Valerian & Valeriana officinalis & 2.09 & Low \\
\hline 31 & Shepherd's purse & Capsella bursa-pastoris & 1.78 & Low \\
\hline 32 & Horsetail & Equisetum arvense & 1.70 & Low \\
\hline 33 & Dill & Anethum graveolens & 1.62 & Low \\
\hline 34 & Garlic & Allium sativum & 1.45 & Low \\
\hline 35 & Mistletoe & Viscum album & 1.20 & Low \\
\hline 36 & Elder & Sambuctus nigra & 1.19 & Low \\
\hline 37 & Chili pepper & Capsicum annuum & 1.05 & Low \\
\hline 38 & Sweet flag & Acorus calamus & 1.00 & Low \\
\hline 39 & Hogweed & Heracleum sphondylium & 0.68 & Low \\
\hline 40 & Wolf's-foot clubmoss & Lycopodium clavatum & 0.37 & Low \\
\hline 41 & Celery & Apium graveolens & 0.25 & Low \\
\hline 42 & Ramson & Allium ursinum & 0.22 & Low \\
\hline
\end{tabular}

The visual examination of the profile of antioxidant activities highlights two or three groups: high antioxidant activity (26.27-46.71\%), group of samples 1-9, moderate antioxidant activity (7.42-21.12\%), group of samples $10-20$, and low antioxidant activity (0.22-4.93\%), last group of samples $21-42$. 


\section{Fuzzy divisive hierarchical clustering}

The partitions obtained applying fuzzy divisive hierarchical clustering (FDHC), using the chromatographic data (without any preprocessing), are presented in Table 2. This fuzzy algorithm provides only two classes in the majority of cases: the first one includes the plant extracts with high and moderate antioxidant activity and the second one the plant samples with low antioxidant activity. In addition, the 2D-representation of the degrees of membership (DOMs) corresponding to the two fuzzy partitions (242 nm) presented in Fig. 1 shows that there are some "anomalies": samples 21 and 22 which belong to the class with low antioxidant activity are classified in the group with high antioxidant activity and samples 14, 16, 18 and 20 are classified wrong as well.

Table 2. The fuzzy clustering results obtained applying fuzzy divisive hierarchical clustering

\begin{tabular}{|c|c|c|c|c|c|c|c|c|c|c|c|c|}
\hline \multirow{2}{*}{ 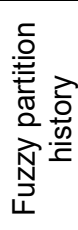 } & \multicolumn{2}{|c|}{$242 \mathrm{~nm}$} & \multicolumn{2}{|c|}{$260 \mathrm{~nm}$} & \multicolumn{2}{|c|}{$280 \mathrm{~nm}$} & \multicolumn{2}{|c|}{$320 \mathrm{~nm}$} & \multicolumn{2}{|c|}{$340 \mathrm{~nm}$} & \multicolumn{2}{|c|}{$380 \mathrm{~nm}$} \\
\hline & 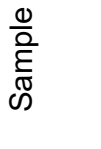 & 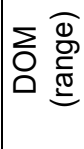 & $\begin{array}{l}\frac{0}{0} \\
\frac{0}{\tilde{\sigma}} \\
\tilde{\infty} \\
\omega\end{array}$ & 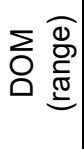 & $\begin{array}{l}\frac{\omega}{0} \\
\frac{0}{E} \\
\infty \\
\infty\end{array}$ & 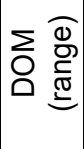 & 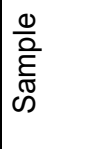 & 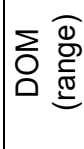 & $\frac{0}{\frac{0}{O}}$ & 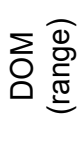 & $\begin{array}{l}\frac{0}{0} \\
\frac{0}{E} \\
\text { ल) } \\
\omega\end{array}$ & 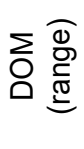 \\
\hline A1 & $\begin{array}{c}13,19, \\
21,6, \\
17,4, \\
10,5, \\
15,11, \\
8,2,3, \\
1,22, \\
9,12,7\end{array}$ & $\mid \begin{array}{c}0.503 \\
- \\
0.714\end{array}$ & $\begin{array}{c}11,27, \\
21,6, \\
19,2, \\
15,4,9, \\
22,5,1, \\
8,3,12, \\
7\end{array}$ & $\begin{array}{c}0.506 \\
- \\
0.707\end{array}$ & $\begin{array}{c}19,6 \\
17,13 \\
9,4,5 \\
1,3,8, \\
12,7\end{array}$ & $\begin{array}{c}0.524 \\
- \\
0.740\end{array}$ & $\begin{array}{c}15,6,1, \\
13,17 \\
3,8,12 \\
7\end{array}$ & $\begin{array}{c}0.509 \\
- \\
0.745\end{array}$ & $\begin{array}{c}11,9 \\
27,15 \\
6,17,1 \\
13,3 \\
12,8,7\end{array}$ & $\begin{array}{c}0.506 \\
- \\
0.732\end{array}$ & $\begin{array}{c}21,3, \\
15,2, \\
27,1,9, \\
5\end{array}$ & $\begin{array}{c}0.514 \\
- \\
0.663\end{array}$ \\
\hline A2 & $\begin{array}{l}33,39, \\
14,27, \\
16,24, \\
23,35, \\
32,38, \\
26,25, \\
29,18, \\
41,42, \\
40,34, \\
37,36, \\
30,20, \\
31,28\end{array}$ & $\begin{array}{c}0.510 \\
- \\
0.943\end{array}$ & $\begin{array}{l}14,39, \\
17,13, \\
24,33, \\
38,35, \\
23,26, \\
16,10, \\
25,29, \\
41,32, \\
42,34, \\
36,37, \\
18,40, \\
30,20, \\
31,28\end{array}$ & $\begin{array}{c}0.505 \\
- \\
0.945\end{array}$ & \begin{tabular}{|c}
14,11, \\
21,15, \\
2,27, \\
22,39, \\
23,24, \\
18,25, \\
26,16, \\
29,41, \\
10,42, \\
35,34, \\
37,38, \\
40,36, \\
30,20, \\
33,32, \\
31,28
\end{tabular} & $\begin{array}{c}0.519 \\
- \\
0.970\end{array}$ & $\begin{array}{c}1,39, \\
27,9, \\
19,21, \\
2,23, \\
24,5, \\
18,26, \\
22,14, \\
20,4, \\
40,16, \\
29,30, \\
41,42, \\
38,34, \\
25,10, \\
37,36, \\
35,33, \\
28,32, \\
31\end{array}$ & $\begin{array}{c}0.526 \\
- \\
0.981\end{array}$ & $\begin{array}{c}39,2, \\
21,22, \\
19,23, \\
24,5, \\
26,18, \\
16,14, \\
20,29, \\
33,30, \\
40,41, \\
42,34, \\
25,36, \\
10,35, \\
38,4, \\
37,28, \\
32,31\end{array}$ & $\begin{array}{c}0.574 \\
- \\
0.971\end{array}$ & $\begin{array}{c}6,11,8, \\
16,25, \\
22,17, \\
19,12, \\
7,14 \\
35,4, \\
33,39 \\
30,10 \\
36,13, \\
29,41, \\
42,34 \\
24,38, \\
23,37, \\
40,20 \\
32,18, \\
31,26, \\
28\end{array}$ & $\begin{array}{c}0.503 \\
- \\
0.986\end{array}$ \\
\hline
\end{tabular}




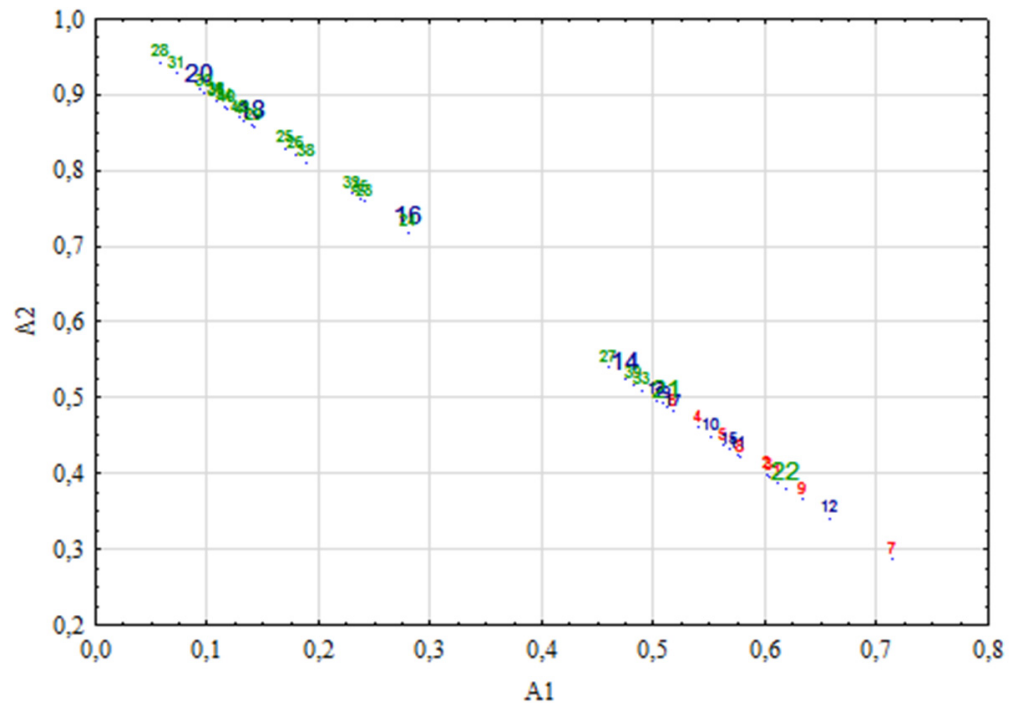

Figure 1. 2-D scatterplot of DOMs corresponding to the two hierarchical fuzzy partitions (A1 and A2)

\section{Principal component analysis}

The results obtained from PCA analysis using again the raw data matrix indicate a significant reduction in the number of variables (Fig. 2).

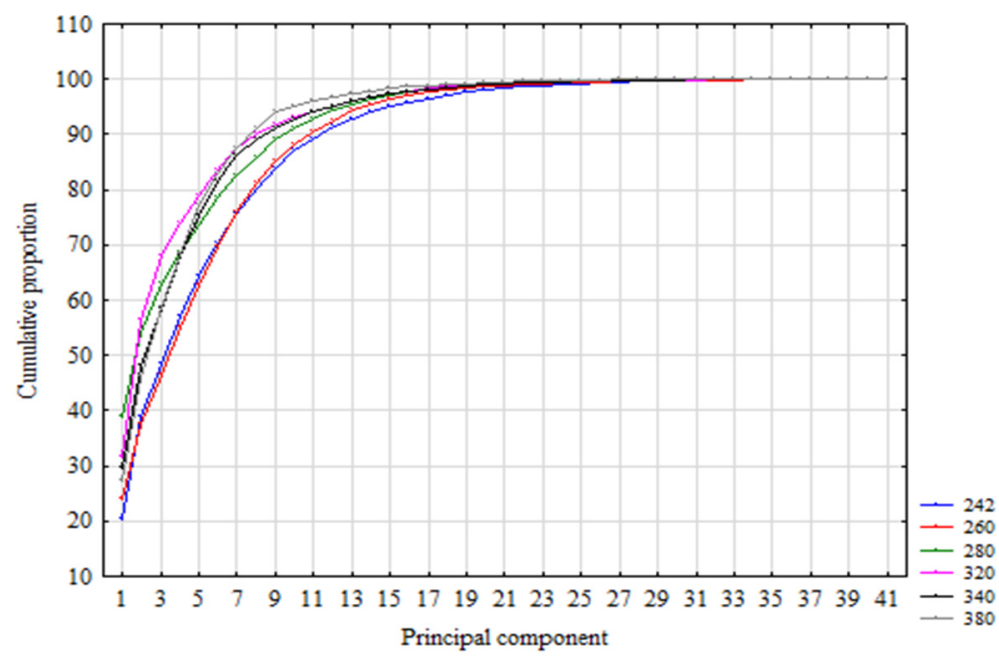

Figure 2. Cumulative proportion profile 
In all cases, the first $41 \mathrm{PCs}$ explain the total variance (100\%) of the data. The variance corresponding to each PC1 is not so different, accounting, for example, more than $38 \%$ (the highest proportion) in the case of data corresponding to $280 \mathrm{~nm}$ detection wavelength and only $20 \%$ (the smallest proportion) for $242 \mathrm{~nm}$ (Table 3). However, surprisingly, the graphical representation of the samples using the first two components corresponding to data obtained at $242 \mathrm{~nm}$, for example, indicates a satisfactory separation of samples according to the antioxidant activity (Fig. 3) in good agreement with the fuzzy clustering results discussed above.

Table 3. Proportion of the first five PC's obtained after PCA method was applied on the data obtained at 242, 260, 280, 320, 340, and $380 \mathrm{~nm}$.

\begin{tabular}{|c|c|c|c|c|c|c|}
\hline \multicolumn{7}{|c|}{ Proportion \% } \\
\hline PC's & $242 \mathrm{~nm}$ & $260 \mathrm{~nm}$ & $280 \mathrm{~nm}$ & $320 \mathrm{~nm}$ & $340 \mathrm{~nm}$ & $380 \mathrm{~nm}$ \\
\hline PC1 & 20.33 & 23.81 & 38.72 & 31.45 & 29.67 & 27.33 \\
\hline PC2 & 18.50 & 13.59 & 15.40 & 24.87 & 18.28 & 18.66 \\
\hline PC3 & 9.58 & 9.07 & 8.96 & 11.54 & 10.50 & 12.62 \\
\hline PC4 & 8.73 & 8.55 & 5.63 & 5.94 & 9.52 & 9.58 \\
\hline PC5 & 7.16 & 7.76 & 4.93 & 5.11 & 7.25 & 8.89 \\
\hline
\end{tabular}

The PC1 profile shows a similar contribution to the separation of the samples according to the antioxidant activity for 242, 260, 280 and $320 \mathrm{~nm}$. It also can be seen a high contribution of PC1 to the separation of sample number 6 (quaking aspen) sample that in a PC1 vs PC2 representation appears as an outlier (Fig. 3). Besides, all the results obtained by applying PCA supports the idea of using the orthogonal and clean scores corresponding to the first 41 PCs in HCA and LDA classification of medicinal plant extracts according to their antioxidant activity.

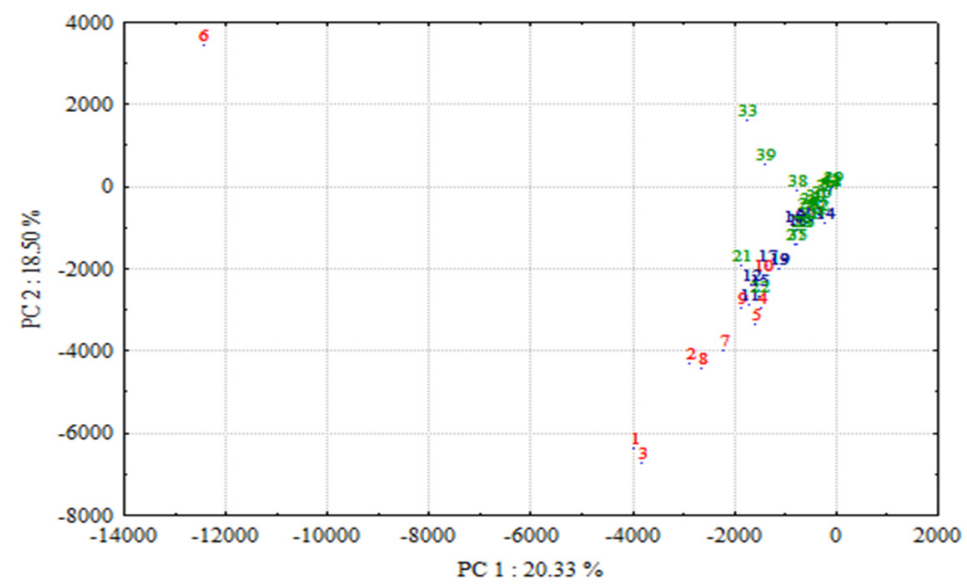

Figure 3. PC1-PC2 scatterplot for the score obtained at $242 \mathrm{~nm}$ 


\section{Hierarchical cluster analysis}

The dendrogram (Fig. 4) was obtained applying the hierarchical cluster analysis (the Ward method as linkage method and Manhattan distance as a measure of similarity) to the data corresponding to the 41 PCs $(242 \mathrm{~nm})$, highlighting well defined groups of plant extracts in good agreement to all the results obtained by using fuzzy clustering method and also PCA. As it can be seen in Fig. 4 there are 2 major clusters: one contains the samples with high and moderate antioxidant capacity with few exceptions (samples 21 and 22), and the group of samples with low antioxidant capacity including the following exceptions, namely $6,10,16,18,19$ and 20 samples. HCA shows samples that are the most similar, that is are the closest in the sense of having the lowest dissimilarity, the group with low antioxidant capacity containing more similar plants regarding the characteristic taken into consideration (antioxidant capacity).

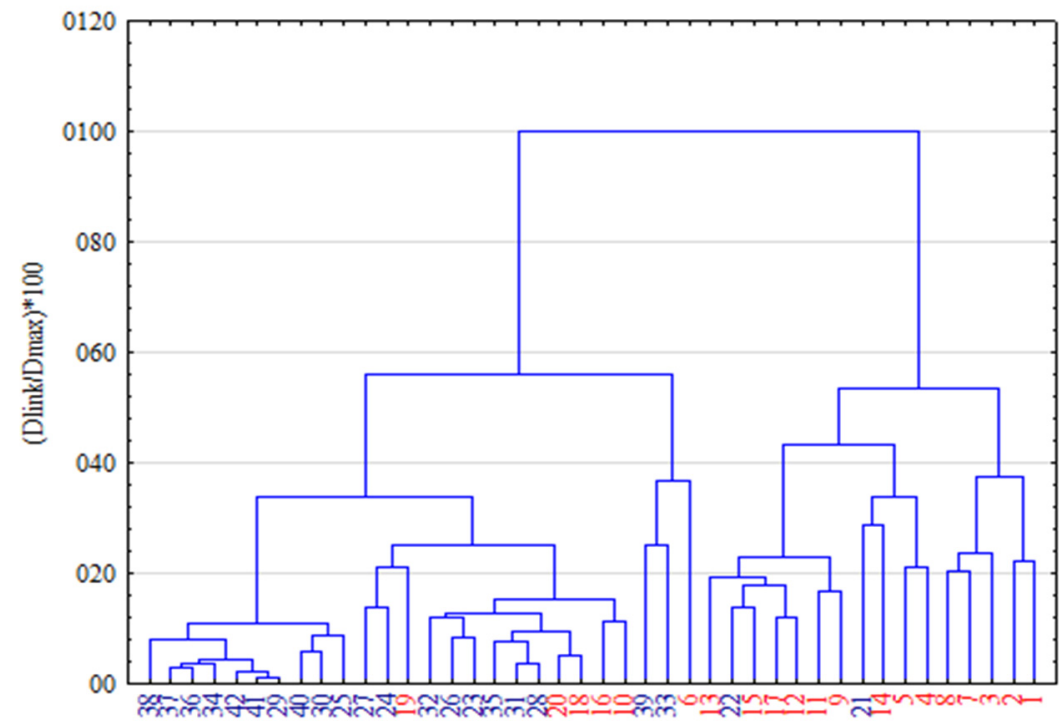

Figure 4. Dendrogram corresponding to the medicinal plant extracts obtained using the Ward method as linkage method and Manhattan distance as a measure of similarity

\section{Linear discriminant analysis}

The combination of PCA with LDA led to the most efficient discrimination of the investigated medicinal plants in two classes. The results obtained applying forward stepwise LDA to the first 41 PCs indicate a very good separation of the samples in almost all cases according to the correct classification rate of original 
PC score data (Table 4): the highest value (100\%) was obtained for raw data in the majority of cases $(242,260,280,320$ and $340 \mathrm{~nm})$ and the lowest value $(78.6 \%)$ for the score data corresponding to the $380 \mathrm{~nm}$. All of the above statements concerning the efficiency of this methodology are well supported by the values of quality performance features obtained by applying the leaveone-out (LOO) cross-validation approach. The results of the cross-validation presented also in Table 4 pointed out a correct classification rate in good agreement to the results obtained for the classification of the original PC score data: the highest value (100\%) was obtained again for the PC score data corresponding to $254 \mathrm{~nm}$ and the lowest value (76.2\%) for the score data obtained at $380 \mathrm{~nm}$.

Table 4. Values of quality performance features from PCA-LDA approach applied to each wavelength $(242,260,280,320,340,380 \mathrm{~nm})$ for medicinal plants classification according to their antioxidant capacity

\begin{tabular}{|c|c|c|c|c|c|c|c|c|c|c|c|c|}
\hline \multirow[b]{3}{*}{ Data } & \multicolumn{12}{|c|}{ DAD wavelength detection } \\
\hline & \multicolumn{2}{|c|}{$242 \mathrm{~nm}$} & \multicolumn{2}{|c|}{$260 \mathrm{~nm}$} & \multicolumn{2}{|c|}{$280 \mathrm{~nm}$} & \multicolumn{2}{|c|}{$320 \mathrm{~nm}$} & \multicolumn{2}{|c|}{$340 \mathrm{~nm}$} & \multicolumn{2}{|c|}{$380 \mathrm{~nm}$} \\
\hline & 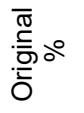 & 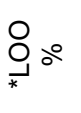 & 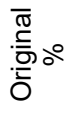 & 엉 & 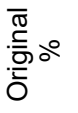 & 옹ㅇ & 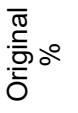 & 엉ㅇㅇ & 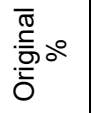 & 잉ㅇ & 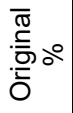 & O잉ㅇㅇ \\
\hline${ }^{2}$ Raw data & 100.0 & 100.0 & 100.0 & 95.2 & 100.0 & 95.2 & 100.0 & \begin{tabular}{|l|}
97.6 \\
\end{tabular} & 100.0 & 92.9 & \begin{tabular}{|l|}
78.6 \\
\end{tabular} & 76.2 \\
\hline${ }^{2}$ Normalized & 88.1 & 85.7 & 100.0 & 97.6 & 100.0 & 97.6 & 95.2 & 90.5 & 85.7 & 78.6 & 92.9 & 85.7 \\
\hline${ }^{2}$ Autoscaled & 100.0 & 97.6 & 100.0 & 90.5 & 100.0 & 95.2 & 95.2 & 90.5 & 100.0 & 100.0 & \begin{tabular}{|l|}
85.7 \\
\end{tabular} & 85.7 \\
\hline${ }^{3}$ Raw data & 92.9 & 90.5 & 85.7 & 81.0 & 83.3 & 76.2 & 85.7 & 78.6 & 85.7 & 76.2 & 69.0 & \begin{tabular}{|l|l}
64.3 \\
\end{tabular} \\
\hline${ }^{3}$ Normalized & 71.4 & 57.1 & 88.1 & 81.0 & 78.6 & 66.7 & 85.7 & 73.8 & 72.9 & 60.3 & \begin{tabular}{|l|}
73.8 \\
\end{tabular} & 73.8 \\
\hline${ }^{3}$ Autoscaled & 88.1 & 81.0 & 92.9 & 81.0 & 83.3 & 76.2 & 76.2 & 64.3 & 85.7 & 76.2 & 90.5 & 78.6 \\
\hline
\end{tabular}

*Leave-one-out validation; ${ }^{2}$ two predefined classes; ${ }^{3}$ three predefined classes

\section{CONCLUSION}

This study used the chromatographic data collected at different wavelengths $(242,260,280,320,340,380 \mathrm{~nm})$ for characterization and classification of medicinal plants according to their antioxidant capacity. The best results, according to the multivariate methods employed are those obtained at $242 \mathrm{~nm}$ detection wavelength (wavelength where the majority of the antioxidant compounds present in the samples are detected). The FDHC including classical methods PCA, HCA and LDA separated the samples into well defined groups with few exceptions: Glycyrrhiza glabra, Gentiana Asclepiades, Chelidonium majus, Juniperus communis, Xanthium spinosum, and Cynara scolymus. The presence of these samples in the wrong class is made according to the concentration 
and not by the type of compounds (compounds that are more or less similar) found in the medicinal plant extracts that have antioxidant activity. The leaveone-out cross-validation also suggested that the samples are divided into two main classes with a correct classification rate of $100 \%$ compared with $90.5 \%$ for three classes. Moreover, this study highlights that the data can be utilized without any preprocessing: the normalization and autoscaling didn't bring any improvements of the clustering results. Another important conclusion of this study is that the scores corresponding to the principal components that explained $100 \%$ of the variance (41 PCs) can be used instead of the initial variables (4501 variables), the same results being obtained, minimizing the speed and time of the analysis.

\section{EXPERIMENTAL SECTION}

\section{Chemicals and plant samples}

The reagents used in this study were of analytical grade, the HPLC grade ammonium acetate and acetonitrile were from Merck (Darmstadt, Germany) and the plant samples belong to Dacia Plant manufacturer (Brașov, România) (Table 1). A number of 42 plant samples commercially available were obtained, according to the manufacturer using different parts of plants and different water: ethanol ratios comprised within the range 35$80 \%$ ethanol. The label that accompanies the alcoholic extracts offers the necessary information regarding the quality of the vegetal material, used to obtain the final products, namely, the plants meet the highest standards of quality, and are procured from their own cultures or partner producers.

\section{The HPLC protocol}

The commercialized extracts were analyzed in order to separate the phytoconstituents using an HPLC-DAD approach. The device used to perform the separation is an Agilent 1200 HPLC system (Waldbronn, Germany) which is equipped with an on-line vacuum degasser, quaternary pump, temperaturecontrolled sample tray, automatic injector, a column thermostat compartment, and a DAD detector. The chromatographic column used to perform the separations was a Zorbax SB-C18 column $(250 \mathrm{~mm} \times 4.6 \mathrm{~mm}, 5 \mu \mathrm{m}$ particle size) also from Agilent. The parameters used were: an injection volume of 30 $\mu \mathrm{L}\left(0.22 \mu \mathrm{m}\right.$ filtered extract), a column temperature of $30^{\circ} \mathrm{C}$ and the flow rate of $1 \mathrm{~mL} / \mathrm{min}$. In order to optimize the method, several preliminary tests were employed using different experimental conditions. The final results were 
obtained (maximum number of compounds separated and maximum resolution) using a multistep isocratic and gradient elution system: solvent $A, 10 \mathrm{mM}$ ammonium acetate $\mathrm{pH} 5$ and as solvent $\mathrm{B}$ acetonitrile. The steps were as follows: $0-2$ min isocratic at $5 \% \mathrm{~B}, 2-10 \mathrm{~min}$ from 5 to $35 \% \mathrm{~B}, 10-20 \mathrm{~min}$ from $35 \%$ to $45 \%$ B, $20-25 \mathrm{~min}$ from $45 \%$ to $95 \%$ B, $25-28$ min from $95 \%$ to $100 \%$ $B, 28-32$ min isocratic at $100 \% B$ and $32-32.1$ min back to $5 \% B$ where was kept until $35 \mathrm{~min}$. The detection of the compounds in the UV-Vis range was performed using the DAD detector that measured the entire spectrum in 240$750 \mathrm{~nm}$ region ( $2 \mathrm{~nm}$ resolution), every 2 seconds and the chromatograms were monitored at 242, 260, 280, 320, 340 and $380 \mathrm{~nm}$. The chromatograms and the mean spectra of the main chromatographic peaks were exported and analyzed using advanced chemometrics.

\section{Antioxidant activity assay}

The antioxidant capacity of the investigated samples was determined using the 2,2-diphenyl-1-picrylhydrazyl (DPPH $\left.{ }^{\circ}\right)$ method. In order to perform the analysis, the extracts needed to be diluted at a dilution rate of 1:50 with a mixture of ethanol-water (60:40). The total radical scavenging capacity (RSC parameter expressed as a percent of consumed DPPH radical) of the hydroalcoholic extracts was measured at $518 \mathrm{~nm}$ (absorbance of DPPH solution) after 30 minutes, the required amount of time for the reaction between DPPH and samples to take place. The ratio between the investigated samples and the DPPH solution ( $150 \mu \mathrm{mol} \mathrm{L}^{-1}$ prepared in ethanol) was $0.1 \mathrm{~mL}: 3 \mathrm{~mL}$. The DPPH solution was daily prepared and protected from light throughout the analysis time in order to minimize the free radical decomposition.

\section{Chemometrics}

Cluster analysis is a large field, both within fuzzy sets theory and beyond it. Clustering and classification are useful since they allow meaningful generalizations to be made about large quantities of data by recognizing among them a few basic patterns. In classical cluster analysis, each object must be assigned to exactly one cluster. This is a source of ambiguity and error in cases of outliers or overlapping clusters and allows a loss of information. This kind of vagueness and uncertainty can, however, be taken into account by using the theory of fuzzy sets introduced by Zadeh in 1965 [27, 28]. A fuzzy set or a fuzzy subset is a collection of ill-defined and not-distinct objects with un-sharp boundaries in which the transition from membership to non-membership in a subset of a reference set is gradual rather than abrupt. The theory of fuzzy set is basically a theory of graded concepts. A central concept in the fuzzy set theory is that it is permissible for an element to belong partly to a fuzzy set (partition). It provides 
an adequate conceptual framework as well as a mathematical tool to model the real-world problems which are often obscure and indistinct, namely fuzzy [29-32].

HCA was extensively used to group experimental variables or samples into clusters, based on similarity within a class and dissimilarity between different classes, according to a predefined criterion. The most common clustering procedure is known to be Ward's method with Euclidean distance as a similarity measure.

LDA is a classification procedure (supervised technique), which needs an initial sample classification into predefined classes. The LDA model contains linear discriminant functions that can classify data, after a predefined criterion. The model is usually validated through leave-one-out classification, which means that each sample is tested, using the model, as an unknown sample. The higher the percentage of correct classification rate by cross-validation, the better the model is. Unlike the other two classical methods, which are clustering/ classification methods, PCA aims to transform the original variables to a new set of variables, uncorrelated and cleaned of noise, called principal components. The high variance of the data set is explained in many cases by the first principal components.

All the graphs and some chemometric methods were performed using Statistica 8.0 (StatSoft, Inc. 1984-2007, Tulsa, USA) software and leave-one-out cross-validation with IBM SPSS Statistics (International Business Machines Corp., New York, USA).

\section{ACKNOWLEDGMENTS}

This work has been supported by the Romanian National Authority for Scientific Research and Innovation (CNCS - UEFISCDI, grant PN-III-P1-1.1-PD2016-0121, contract no. 14/2018).

\section{REFERENCES}

1. M. Yan; M. Chen; F. Zhou; D. Cai; H. Bai; P. Wang; H. Lei; Q. Ma; J. Pharm. Biomed. Anal., 2019, 164, 734-741.

2. R. A. Dar; M. Shahnawaz; P. H. Qazi; J. Phytopharmacol., 2017, 6, 349-351.

3. WHO monographs on selected medicinal plants, Volume 4, 2009.

4. M. Al-Fatimi; J. Ethnopharmacol., 2019, 241, 111973. doi:https://doi.org/10.1016/j.jep.2019.111973.

5. B. A. R. Hassan; Pharmaceut. Anal. Acta., 2012, 3, DOI: 10.4172/2153-2435.1000e139 
6. M. A. Motaleb; Selected medicinal plants of Chittagong hill tracts, IUCN, Dhaka, 2011.

7. F. Jamshidi-Kia; Z. Lorigooini; H. Amini-Khoei; J. Herbmed. Pharmacol., 2018, 7, 1-7.

8. M. Rafieian-Kopaei; J. Herb. Med. Pharmacol., 2012, 1, 1-2.

9. S. Guo; X. Cui; M. Jiang; L. Bai; X. Tian; T. Guo; Q. Liu; L. Zhang; C.-Tang Ho; N. Bai; J. Food. Drug. Anal., 2016, 30, 1-8.

10. R. Singh; J. Plant. Sci., 2015, 3, 50-55.

11. F. Jamshidi-Kia; Z. Lorigooini; H. Amini-Khoei; J. Herbmed. Pharmacol., 2018, 7, 17.

12. M. Esteki; Z. Shahsavari; J. Simal-Gandara; Food Res. Int., 2019, 122, 303-317.

13. T. O. Obafemi; A. C. Akinmoladun; M. T. Olaleye; A. Onasanya; K. C. Komolafe; J. A. Falode; A. A. Boligon; M. L. Athayde; J. Appl. Pharm. Sci., 2017, 7, 10-118.

14. Z. Akar; N. A. Burnaz; Food Sci. Technol., 2019, doi:https://doi.org/10.1016/ j.Iwt.2019.05.110

15. A. A. Boligon; M. L. Athayde; Austin Chromatogr., 2014, 1, 1-2.

16. S. M. Dhole; P. B. Khedekar; N. D. Amnerkar; Pharm. Methods, 2012, 3, 68-72.

17. Y. Zhao; X.-Min Youb; H. Jiang; G.-Xin Zoub; B. Wanga; J. Chromatogr. B, 2019, $1104,11-17$.

18. A. S. Rathore; S. Joshi; Process Analysis: High Performance Liquid Chromatography, Elsevier, New Delhi, 2018.

19. O. Deveoglu; E. Torgan; R. Karadag; Color. Technol., 2012, 128, 133-138.

20. J. Lozano-Sanchez; I. Borras-Linares; A. Sass-Kiss; A. Segura-Carretero; Chromatographic Technique: High-Performance Liquid Chromatography (HPLC), Modern Techniques for Food Authentication, Elsevier, 2018.

21. Q. Nie; S. Nie; High-performance liquid chromatography for food quality evaluation, Evaluation Technologies for Food Quality, Elsevier, 2019.

22. I. A. Sima; C. Sârbu; R. D. Nașcu-Briciu; Chromatographia, 2015, 78, 13-14.

23. S. P. Mishra; U. Sarkar; S. Taraphder; S. Datta; D. P. Swain; R. Saikhom; S. Panda; M. Laishram; Int. J. Lives. Res., 2017, 5, 60-78.

24. R. G. Brereton; Applied Chemometrics for Scientists, John Wiley \& Sons: Ltd. Chichester, 2007.

25. I. A. Sima; M. Andrási; C. Sârbu; J. Chromatogr. Sci., 2018, 56, 49-55.

26. C. Sârbu; R. D. Nașcu-Briciu; A. Kot-Wasik; S. Gorinstein; A. Wasik; J. Namieśnik; Food Chem., 2012, 130, 994-1002.

27. L. A. Zadeh; Inf. Control., 1965, 8, 338-353.

28. F. Hoppner; R. K. Klawonn; T. Runkler; Fuzzy Cluster Analysis, John Wiley \&Sons, Ltd. Chichester, 1999.

29. H. Pop; D. Dumitrescu; C. Sârbu; Anal. Chim. Acta, 1995, 310, 269-279.

30. H. Pop; C. Sârbu; O. Horovitz; D. Dumitrescu; J. Chem. Inf. Comput. Sci., 1996, 36, 465-482.

31. C. Sârbu; K. Zehl; J. W. Einax; Chemom. Intell. Lab. Syst., 2007, 86, 121-129.

32. C. Sârbu; H. F. Pop; Fuzzy Soft-Computing Methods and Their Applications in Chemistry in Reviews in Computational Chemistry, K.B. Lipkowitz, R. Larter and T. R. Cundari (eds.), Wiley-VCH, 2004, Chapt. 5, 249-332. 